\title{
NOTÍCIAS BIBLIOGRÁFICAS
}

\author{
ORFÃOS DE REALIDADE \\ considerações a partir da leitura de \\ ORFÃOS DE UTOPIA - A melancolia da Esquerda, de Ernildo Stein
}

Sergio Bolliger ${ }^{1}$

Aquele que é ou foi "de esquerda" năo pode ficar indiferente à leitura de ORFĀOS DE UTOPIA. É dele que o livro fala. O livro, como tantos livros, fala de opções politicas e da ética, da moral e da revolução. Mas, à sua leitura, parece não ser exatamente esse o seu assunto. Percebe-se: o livro trata é do leitor.

ORFÃOS DE UTOPIA teve sua primeira edição em 1993. Escrito quando do desmonte do lugar da esquerda no mundo, ofereceu, ao contrário da esmagadora maioria do que se escrevia então, acolhida respeitosa, generosa e solidária para quem não tinha mais lugar no mundo. Mas que lugar poderia ser oferecido a esse leitor então, quando nem ao menos 0 não-lugar da utopia estava à disposição? Ao invés da utopia deslegitimada ou da realidade resignada, o livro apontava para o lugar a-tópico do leitor, para ele mesmo como o próprio lugar: o leitor sem mundo, o leitor melancólico.

ORFÃOS DE UTOPIA foi talvez a primeira publicação a relacionar essa crise das esquerdas com a melancolia. Melancolia, aí, entretanto, não resumia um diagnóstico psicopatológico do "homem de esquerda" de 93. A melancolia não fechava o quadro de análise. Ao contrário, abria a sua possibilidade.

Podemos talvez dizer que a melancolia, em 93, era o modo como se fazia presente um mundo então tornado ausente: o mundo do ser politico de esquerda. O livro fala da presença desse mundo ausente, mundo de opções politicas e da ética, da moral e da revolução. Fala da melancolia, para poder dizer desse mundo. Percebe-se agora: o livro fala do leitor presente para poder dizer da política ausente.

Poderíamos talvez ainda acrescentar: esse dizer da politica ausente, que poderia se dar no espaço aberto por uma disposição melancólica, e que seria capaz de pensar a política para além de sua presença, seria também um dizer tocado pela filosofia. Aponta Stein, no pós-escrito "Melancolia: aspectos analíticos-existenciais":

"Na obra de Martin Heidegger encontramos uma passagem em que ele se pergunta acerca da existência de uma determinada tonalidade psicológica ou animica, condição para a filosofia. E Heidegger faz um jogo terminológico com o qual ele acaba por introduzir a questão da melancolia.

Arquiteto e mestrando de Filosofia do Instituto de Filosofia e Ciências Humanas da Universidade de Campinas - UNICAMP.

\begin{tabular}{|l|l|l|l|l|l|}
\hline VERITAS & Porto Alegre & v. 45 & n. 1 & Março 2000 & p. 137-180 \\
\hline
\end{tabular}


(...) A melancolia seria, pois, uma espécie de estado de tensão formal no qual o filósofo desenvolve a sua atividade. E Heidegger remete, ao falar disso, a Aristóteles. E, já em Aristóteles, fala-se de que os grandes na filosofia, na arte e na politica, de alguma maneira, foram melancólicos. $\mathrm{B}$, nesse sentido, a filosofia viveria sob o signo da melancolia. ${ }^{n^{2}}$

Pode-se dizer, com isso, que a fala da melancolia, ao permitir esse dizer da política ausente, também abriria, ao homem político, a possibilidade para um dizer do lugar de onde vem o "político" e, assim, para um verdadeiro diálogo entre a esquerda e a filosofia, para além de todas as dificuldades enfrentadas durante o século XX, quando o brilho da voz política, então presente, ofuscava seu lugar de origem.

Esse é, a meu ver, o lugar que o livro ofereceu e pode continuar oferecendo àqueles que, da esquerda, foram então expelidos para fora do mundo, para a melancolia. Para que se pudesse chegar ao lugar apontado pelo livro, entretanto, seria preciso superar o caráter patológico dessa melancolia presente.

No capítulo chamado "Utopia e Melancolia", distingue-se a "melancolia política", "criadora", da "melancolia patológica, destruidora". Esses termos săo empregados por Stein na descrição do que chamou de "caminhos de sinais contrários da melancolia". 30 falar dos caminhos da melancolia, entretanto, o livro fala também da utopia como seu lugar de chegada e de partida. No capitulo acima citado, a vinculação entre utopia e melancolia é apresentada, esquematicamente, da seguinte maneira:

“a) a melancolia (política) em si gera processos utópicos.

b) a utopia na sua crise e seu desaparecimento gera melancolia (patológica)." ${ }^{4}$

Disso se segue que uma possivel inversão de sinais da trilha melancólica, isto é, a possibilidade da reconversão de patologia destruidora em política criadora, passaria pelo enfrentamento da questão da perda da utopia.

Mais especificamente, em relação à crise presente, o livro apresenta a tese de que seria necessária a elaboração da melancolia enquanto luto pela perda da utopia socialista.

Passados cinco anos da publicação do livro, é tempo de nos perguntarmos se a esquerda foi ou está sendo capaz dessa elaboração, proposta como tarefa nos seguintes termos:

"Uma imensa tarefa cabe àqueles que estão confundidos com a perda de ideais utópicos do socialismo e a elaboração necessária do luto, para que não se converta num mero processo de ressentimento e de compensação, a ação futura em busca de alternativas que sempre terão diante de si o desafio das utopias." ${ }^{5}$

Estes meus "comentários" não pretendem, de forma alguma, abranger o amplo espectro de referências abertos pelo livro. Tampouco, fazer uma espécie de balanço do que pode a esquerda fazer de si em cinco anos. Pretendem apenas:

1. fornecer uma sugestão de leitura da questão da elaboração do luto da esque rda, a partir de apenas uma das referências indicadas na obra de Stein, o ensaio Luto e Melancolia, de Freud;

2. fazer, a partir dessa leitura, uma avaliação de dificuldades para que esse trajeto de luto possa ser trilhado pela esquerda, ou, pelo menos, pela sua fração dita marxista.

Stein, p. 83 e 84 .

Stein, p. 42.

idem.

Stein, p. 11. 
Partimos de uma distinção, feita no texto de Freud, entre luto e melancolia. Para Freud, o luto se diferencia da melancolia por ter um objeto sobre o qual elaborar sua perda. Já a melancolia, apresenta-se sem objeto, como um estado difuso, onde não se sabe muito bem o que é que o melancólico perdeu. Em ambos os casos, um "mundo" perde sentido; mas, no luto, sabe-se o que doava o sentido perdido e elabora-se sua perda enquanto perda do objeto. A melancolia, por outro lado, näo permite uma elaboração do mesmo tipo, por carência, para o melancólico, do objeto de sua perda.

A tarefa proposta no livro de Stein diz da necessidade de elaboração da melancolia enquanto luto. Lendo essa proposta a partir do texto de Freud, poderiamos dizer que está implícito aqui que a melancolia năo pode, enquanto melancolia, elaborar seu objeto de perda, porque não o tem. Teria que ser transmutada em luto, o que só seria possível se pudesse ter acesso a um possivel objeto de sua perda.

Pois bem: o livro de Stein propỏe a utopia socialista como objeto perdido da melancolia de esquerda. Ele aponta para o objeto e, ao fazê-lo, estaria dado um primeiro passo para que, uma vez o objeto sendo encontrado, esse encontro permitisse que a melancolia pudesse ser elaborada como luto, no sentido freudiano.

Entretanto, dado o primeiro passo, seria necessário que a esquerda desse o seu, indo ao encontro do objeto. Porém, pode-se pensar em grandes dificuldades para que esse segundo passo seja dado, de forma a haver a aceitação desse objeto da perda, enquanto tal, pela esquerda.

Como diz o prefácio de Décio Freitas, "não havia certamente, para um esquerdista, nada mais provocativo e ultrajante do que chamar de utópico o projeto socialista". ${ }^{6}$ Isso vale, especificamente, para o marxista que recusa "ideais utópicos" (deixados a anarquistas, cristãos etc.).

Isso posto, a "perda" não poderia aparecer, para essa esquerda marxista, como "perda da utopia". O marxista compreende-se ainda, mesmo como ex-marxista, como recusando "fantasias utópicas" e elaborando sobre "concepções científicas da realidade". Assim, a "perda" não pode atingi-lo, de forma a que venha sentir-se "órfão de utopia". O marxista sente-se órfão de realidade.

A realidade, entretanto, não é um "objeto" sobre o qual se possa elaborar a perda. Ao perder a realidade, o perdedor perde-se com ela. Daí a melancolia (no sentido patológico freudiano): nela, não nos distinguimos do objeto que morreu, morremos com ele. Ao contrário do luto, onde quem perde ainda guarda os contornos de si em relação ao que está morto; o enlutado pode querer morrer também, mas esse é seu problema: estar vivo sem o outro. Já o problema do melancólico é estar, ele mesmo, morto.

Ao final da introdução de seu livro, Stein sugere que as utopias sejam "um outro modo de realização do mito de Sísifo", comparando o obstinado recomeço no mito às tarefas hoje colocadas para a esquerda. A "realidade objetiva" da "concepção científica de realidade" marxista, entretanto, não pode ser recomeçada como uma pedra a ser rolada montanha acima. Essa "realidade" simplesmente se impõe. Se não mais a reconhecemos, não somos. Se, por outro lado, reconhecemos a "realidade" como outra, não aquela que supúnhamos que fosse, só nos restaria, então, rendermo-nos a ela. Essa seria a forma "maníaca" de se relacionar com a perda, variante possível, apontada por Stein, de patologia alternativa à melancólica.?

Prefácio à segunda edição, p. 7 .

P. 48. 
Creio que se pode entender "elaborar a perda" como conduzir-se de maneira a poder continuar sendo sem aquilo que não é mais (o que se perdeu); isso implica em deixar não ser aquilo que já não é mais, subentendido que quem "deixa" algo, o faz porque continua sendo. Para isso, é preciso ser para além do que não é mais. Se o que não é mais é certa "realidade", para elaborar a perda do socialismo, a esquerda precisaria transcender a sua realidade e compreendê-la.

O livro de Stein convida a isso, em um processo entendido enquanto "elaboração positiva da perda". "Entretanto, creio que essa elaboração exigiria uma esquerda já em condições de compreender-se para além de sua "realidade" e, assim, poder aceitar:

1. que o objeto da perda é o socialismo enquanto utopia, que deve ser abandonado; e

2. que elaborar essa perda é recomeçar a construir o sentido da esquerda enquanto utopia (não a socialista), através de novos investimentos emocionais. ${ }^{{ }^{\circ}}$

Não vejo como, entretanto, ser da opinião de que a esquerda esteja, digamos, "liberada" de sua realidade anterior, para esses novos investimentos. A esquerda ainda está em sua "realidade". Seja morta, na melancolia; seja "mudada", na "mania". E, portanto, propensa a concluir, com o livro, melancolicamente, que:

1. como tudo não passava de utopia, estou morto; $\mathrm{e}$

2. não vale a pena rolar pedra montanha acima, se for para construir uma "mera utopia".

Ou, à maneira maníaca, que:

1. a realidade demonstrou que tudo não passava de utopia, portanto matéria para a "Lata de Lixo da História"; e

2. agora temos mais o que fazer do que cuidar de ideais utópicos.

O reconhecimento do conceito de socialismo como "operativamente vazio" não libera a esquerda para uma tal "elaboração positiva". Esse reconhecimento estaria ainda coincidindo com o reconhecimento (ex-)marxista de que socialismo era, afinal de contas, utópico. E o ex-marxista não recupera o mundo a partir da utopia; ao contrário, ele percebe que perdeu o mundo, a partir do momento que percebe sua inserção nele como fundada na utopia. O caráter de utopia se impõe (indesejável) como perda, por parte do socialismo, de fundamento na "realidade", que subsiste como conceito marxista, no "ex-marxismo".

O livro mesmo sugere que a "elaboração positiva" tende a ser impedida pela sobrevivência de "processos compensatórios" e superveniência de "ressentimentos". Mesmo sendo isso correto, como parece ser, não creio que esse esclarecimento possa preparar um terreno comum para o diálogo com a esquerda, em sua "realidade"; posto que tais conceitos não atingem essa "realidade".

Para uma tentativa de restabelecimento de um diálogo positivo entre filosofia e esquerda, creio ser necessária uma investigação do que seria a "realidade", para a esquerda marxista. Investigação essa que estabelecesse bases mais próximas de diálogo, para que possa ser pensado, no âmbito de uma (co-)elaboração, o que é que a esquerda perdeu.

Poderíamos nos perguntar, após ler o livro, qual seria o fundamento da "realidade" da militância socialista; fundamento esse que, agora inexistente, a desvendaria como utopia. 
Não acho possivel dizer que o fundamento dessa "realidade" teria sido a realidade concreta de estados socialistas, com seu "socialismo real". Isso, porque muitos nunca os tiveram como referência de socialismo e mesmo lutaram pela derrubada dos regimes burocráticos. E, no entanto, o fim dos Estados do Leste não liberou o mundo para o "verdadeiro socialismo", e mesmo esses socialistas democráticos também podem se encontrar, hoje, imersos em melancolia ou dispersos de forma maníaca. Não se sabe bem o que esses perderam, mas é certo que algo "caiu” para além dos regimes burocráticos.

O fundamento de "realidade" do socialismo não teria sido, tampouco, modelos alternativos de um "verdadeiro" socialismo que tivesse presidido a prátíca. Isso, porque nada havia de muito elaborado enquanto modelo de futuro. Não havia propriamente o desenvolvimento "formal" de uma utopia e que hoje não mais pudesse se sustentar. Havia teoria crítica do existente e modelos de revolução, do "pôr-se a caminho" do socialismo, mas não propriamente desse último. Creio poder me aproximar da natureza da realidade do socialismo ao dizer que ele foi, em certo sentido, uma "utopia prática", onde não cabia uma formalização da "utopia", enquanto tal. Daí, talvez, a vigência do fenômeno identificado, no livro, como "atuação", na prática da militância socialista.

O fundamento "real" do socialismo não teria sido, tampouco, sua "inevitabilidade", justamente porque, sem a intervenção militante do socialista, ele não aconteceria. O socialismo tinha o caráter de uma possibilidade. Não uma possibilidade lógica, fundada em modelos abstratos; e sim uma possibilidade "real", prática, no sentido que exigia, para existir enquanto possibilidade, "nossa praxis".

O socialismo, assim, não tinha sua "realidade" em uma concreção (institucional), em um modelo alternativo (utopia formal) ou numa crença de inevitabilidade (mecanicista). Mas creio que nos aproximamos de sua realidade ao examinarmos como ele se constituía, para o militante, enquanto praxis.

Essa praxis, para o militante, não era entendida como voluntarista. Ela não era entendida como determinada apenas pela vontade (subjetiva), pois o seu "sentido" não provinha do indivíduo, da coleção de indivíduos, do partido ou da classe. O seu sentido provinha do sentido positivo da História, objetivamente dado.

Esse sentido positivo era constituído, para o marxista, pelo desenvolvimento das forças produtivas. A praxis era entendida como intervenção para liberação das "forças produtivas" das relações capitalistas de produção (e, para alguns, também das "deformações" burocráticas, a leste), para que pudessem ter o seu curso de desenvolvimento. E para evitar que, atadas essas forças pelas relaçōes capitalistas (e pela Burocracia), a História ficasse determinada em seu sentido negativo, com a destruição de forças produtivas (a barbárie).

Essa intervenção, assim, buscava liberar aquilo que daria, ele mesmo, o sentido da intervenção: o desenvolvimento das forças produtivas. O que, assim, conferia "realidade" ao socialismo, expulsando o qualificativo de "utopia", era o fato de existir um "Deus da Técnica conspirando a nosso favor" e aguardando que fosse liberado dos entraves das relações capitalistas de produção (e da Burocracia).

Foi em nome do desenvolvimento das forças produtivas que a militância se pôs a caminho do socialismo, deixando a "Ele" a responsabilidade (objetivada) do conteúdo do sentido histórico. Aos militantes cabia "cumprir sua parte"; possivelmente, assim, alienando a liberdade da responsabilidade individual, que é apontada, na introdução do livro, como meta agora recolocada em dia.

Foi também em nome do desenvolvimento das forças produtivas que foi dado apoio a tendências "progressistas" não socialistas e até anti-socialistas (em nome "Dele", era possível transigir). Em nome dele e do sentido que dava à História, fundou-se a moral militante. Não em nome de pátrias socialistas, mas em nome do Sentido da História. Em nome do Sentido da História entraram em forma pelotões de fuzilamento. 
Acredito mesmo que a "moral revolucionária" só se permite ser discutida a partir do enfrentamento desse conceito amoral e absoluto, único conceito a-histórico da esquerda marxista, que funda, para ela, o próprio sentido da História e que, muitas vezes, se banaliza como o sentido da produtividade e acumulação crescentes.

Isso tudo leva-me a cogitar que a utopia socialista, então, teria consistido na utopia de conluio com esse "Deus da Técnica conspirando a nosso favor". E sua perda, na perda desse conluio. Pois aconteceu que o socialismo "real" não liberou as forças produtivas; ao contrário, aprisionou-as. E a liberação das forças produtivas das peias da Burocracia, por sua vez, não pôs na ordem do dia o socialismo democrático. E aquele Deus, enfim, ao que tudo indica, teria abandonado os socialistas pela via capitalista da terceira revolução industrial. Se essa é a perda, aquilo que o melancólico chora é a expulsão do convivio divino. Já o maníaco, esse se ajoelha ante o novo (neo) altar onde Deus foi morar.

Curiosamente, em ambos os casos, Deus não morreu. E impede a elaboração da perda do socialismo enquanto luto. A elaboração da perda do socialismo não pode, como na superação de um luto, ter o caráter de poder abandonar algo que foi querido, do tipo "aquilo foi uma coisa boa e importante para mim, mas agora acabou e eu, restabelecido da perda, passo a novos investimentos emocionais".

O luto, segundo o Freud de "Luto e Melancolia", não implica em perda de auto-estima ou ressentimento contra o objeto de perda. A melancolia, ao contrário, sim. Para Freud, o melancólico não pode ser comparado a uma viúva de um esposo amado; ele poderia ser melhor comparado a uma noiva abandonada na porta da igreja. Noiva que passaria a desenvolver sentimentos ambíguos em relação ao noivo, voltando sua agressividade contra si mesma, dizendo, como um ex-socialista, "como pude ser tão burra, poder perder tanto tempo da minha vida? ${ }^{10}$

Assim, creio que, para discutir uma elaboração positiva da melancolia de esquerda, seria preciso enfrentar o conceito de desenvolvimento das forças produtivas", que permanece, de fato, impensado e intocado, talvez, enquanto uma utopia ainda presente e mais fundamental: a utopia do conhecimento do Sentido da História.

\section{Obras Citadas}

FREUD, Sigmund. Duelo y Melancolia, in Obras Completas, Tomo II. Madrid, Biblioteca Nueva, 1981. STEIN, Ernildo. Orfäos de Utopia: a Melancolia de Esquerda. Porto Alegre, Editora da Universidade/UFRGS, 1996.

${ }^{10}$ Cf. Freud, p. 2092 